\title{
BUDAYA ORGANISASI, DAN KOMPENSASI TERHADAP KEPUASAN KERJA PEGAWAI \\ (STUDI KASUS DIVISI MIKRO PT. BANK MANDIRI AREA CIKINI JAKARTA PUSAT)
}

\author{
Lusiana Lusiana ${ }^{1}$, Indupurnahayu Indupurnahayu ${ }^{2}$, Akhmad Bakhtiar Amin ${ }^{2}$ \\ ${ }^{1}$ Bank Mandiri-Jakarta, ${ }^{2}$ Universitas Ibn Khaldun Bogor \\ Email: lusi_ana_agam@yahoo.com
}

\begin{abstract}
ABSTRAK
Penelitian ini bertujuan menganalisa pengaruh pada tingkat kualitas sumberdaya manusia terhadap kepuasan kerja pegawai Mikro Area Jakarta Cikini. Tehnik Pengambilan data mengunakan kuesioner yang diberikan kepada Pegawai Mikro Area Cikini sebanyak 110 orang.hipotesa yang digunakan adalah SEM (Structural Equation Modelling.

Hubungan budaya organisasi terhadap kepuasan kerja di Divisi Mikro Bank Mandiri Area Cikini Jakarta Pusat sebesar 0,757 dengan taraf signifikansi 0,00 artinya bahwa pengaruh variable budaya organisasi terhadap kepuasan kerja tergolong sangat kuat, pengaruh kualitas sumberdaya manusia terhadap kepuasan kerja di Divisi Mikro Bank Mandiri Area Cikini Jakarta Pusat sebesar 0,877 dengan taraf signifikansi 0,00, / pengaruh kompensasi terhadap kepuasan kerja di Divisi Mikro Bank Mandiri Area Cikini Jakarta Pusat sebesar 0,991 dengan taraf signifikansi 0,00 artinya bahwa pengaruh variable kompensasi terhadap kepuasan kerja tergolong sangar kuat secara nyata bahwa kepuasan kerja akan meningkat jika kompensasi meningkat pula.
\end{abstract}

\section{Kata Kunci: Budaya Organisasi, kompensasi, kepuasan kerja, SEM}

\begin{abstract}
This study aims to Analyzing the influence of the quality of human resources on job satisfaction of the employees of Area Micro Jakarta Cikini. Data collection techniques using questionnaires given to Cikini Area Micro Officers as many as 110 people. The hypothesis used is SEM (Structural Equation Modeling.

Organizational culture relationship to job satisfaction in Micro Division of Bank Mandiri Area Cikini Central Jakarta of 0.757 with significance level 0,00 means that the influence of organizational culture variable on job satisfaction is very strong, the influence of quality of human resources to job satisfaction in Micro Division of Bank Mandiri Area Cikini Central Jakarta 0,877 with significance level 0,00, / influence of compensation to job satisfaction in Micro Division of Bank Mandiri Area Cikini Central Jakarta equal to 0,991 with significance level 0,00 mean that influence of variable of compensation to job satisfaction pertained strong strongly that job satisfaction will increase if compensation increases as well
\end{abstract}

Keywords: Organization Culture, Compensation, Work Satisfaction, SEM 


\section{PENDAHULUAN}

Tujuan dunia perbankan Indonesia saat adalah menunjang pelaksanaan tingkat pembangunan nasional dalam rangka meningkatkan pemerataan, pertumbuhan ekonomi, dan stabilitas nasional ke arah peningkatan kesejahteraan rakyat banyak yang lebih merata. Perbankan adalah suatu lembaga keuangan, Definisi Bank menurut Undang-Undang RI Nomor 10 Tahun 1998 Bank adalah badan usaha yang menghimpun dana dari masyarakat dalam bentuk simpanan dan menyalurkannya kepada masyarakat dalam bentuk kredit dan atau bentuk-bentuk lainnya dalam rangka meningkatkan taraf hidup rakyat banyak. Bank menurut pendapat saya adalah suatu lembaga keuangan yang berguna untuk melakukan kegiatan keuangan masayarakat tempat menyimpan dan menyalurkan pinjaman ke pada rakyat, dimana uang hanya tempat wadah mengelola uang dari rakyat untuk raykat. Asas perbankan Indonesia adalah demokrasi ekonomi dengan menggunakan prinsip kehati-hatian. Fungsi utama perbankan Indonesia adalah sebagai berikut. a) Penghimpunan dana dari masyarakat, Simpanan adalah dana yang dipercayakan masyarakat pada bank berdasarkan perjanjian penyimpanan dana dalam bentuk giro, deposito, sertifikat deposito, tabungan, dan atau bentuk Iainnya yang dipersamakan dengan itu. b) Penyalur dana (pemberi kredit), Kredit adalah penyediaan uang atau tagihan yang dapat dipersamakan dengan itu berdasarkan persetujuan yang diwajibkan pihak peminjam untuk melunasi hutangnya setelah jangka waktu tertentu dengan pemberian bunga.

Sedangkan menurut Hasibuan (2005:2), pengertian bank adalah badan usaha yang kekayaannya terutama dalam bentuk asset keuangan (financial assets) serta bermotif profit juga sosial, jadi bukan hanya mencari keuntungan saja.

Kasmir (2008:2) berpendapat bahwa bank merupakan lembaga keuangan yang kegiatannya menghimpun dana dari masyarakat dalam bentuk simpanan kemudian menyalurkan kembali ke masyarakat, serta memberikan jasa-jasa bank lainnya.

Bank Mandiri Tbk (BMRI) diterangkan semakin agresif melakukan digitalisasi secara masiv dengan terus mendorong transaksi elektronik. Sebagai realisasi komitmen pada tujuan pemerataan pembangunan, Bank Mandiri telah memberikan KUR sebesar Rp13,3 triliun atau mencapai $102,6 \%$ dari target. Penyaluran kredit di sektor produktif pada produk KUR (Kredit Usaha Rakyat) sebesar 40\% juga dijalankan Bank Mandiri sejak 2007. Hingga Juni 2017, Bank Mandiri telah menyalurkan KUR sebesar Rp 40,8 triliun kepada 874.821 debitur di 
seluruh Indonesia. Sedangkan Di semester I/2017 jumlah KUR yang dikucurkan sudah mencapai 45\% dari target sebesar Rp 13 triliun atau setara dengan $\mathrm{Rp}$ 5,8 triliun.

Strategi lain adalah menguatkan dua produk mikro unggulan yaitu Kredit Usaha Mikro (KUM) dan Kredit Serbaguna Mikro ( KSM). Kedua produk ini didesain agar dapat mendukung perkembangan usaha debitur melalui skim kredit yang menarik dan bunga bersaing. Beragam upaya yang dijalankan Bank Mandiri, mempengaruhi dengan signifikan kualitas pembiayaan mikro Bank Mandiri, terlihat dari Non Forformen loan (NPL) atau rasio kredit bermasalah di segmen ini terjaga hanya $2,4 \%$.

Penyaluran Kredit Mikro terbagi dari 2 kategori diantaranya adalah :

\section{KUM (Kredit Usaha Mikro)}

Kredit Usaha Mikro khusus diberikan kepada Usaha Mikro dengan maksimum limit kredit sebesar Rp 100 juta. Khusus untuk fasilitas top up diperkenankan sampai dengan limit Rp 200 juta.

\section{KSM (Kredit Serbaguna Mikro)}

Untuk pembiayaan berbagai macam keperluan (serbaguna), selama tidak melanggar kesusilaan, ketertiban umum dan bertentangan dengan hukum dengan maksimum limit kredit sebesar 1 Milyar Khusus untuk PNS dan BUMN.

\section{Persyaratan Calon Debitur}

\section{Kredit Usaha Mikro (KUM)}

- Usaha minimum 2 tahun di lokasi dengan bidang usaha yang sama.

- Usia minimal 21 tahun atau sudah menikah. Maksimal usia 60 tahun saat kredit lunas.

- Melampirkan bukti diri berupa Kartu Tanda Penduduk (KTP), Kartu Keluarga (KK) serta Surat Nikah (bagi yang menikah).

- Khusus kredit Rp 50 juta keatas dipersyaratkan NPWP,TDP.

- Surat Keterangan Usaha dari Kelurahan, Dinas Pasar atau Otorita setempat dimana yang bersangkutan memiliki usaha ; atau

- Surat Ijin Usaha

- Belum pernah memperoleh fasilitas kredit atau pernah / telah memperoleh fasilitas kredit dengan kolektibilitas Lancar atau tidak dalam kondisi kredit bermasalah.

\section{Kredit Serbaguna Mikro (KSM)}

- Warga Negara Indonesia yang berdomisili di Indonesia.

- Telah diangkat menjadi pegawai tetap minimal 1 (satu) tahun dan berpenghasilan tetap. Khusus untuk pegawai dengan status tetap (tidak termasuk masa percobaan/ probation) dan payroll di Bank maka masa kerja pegawai tidak diperhitungkan.

- Usia minimal 21 tahun atau sudah menikah dan pada saat kredit lunas sesuai usia pensiun yaitu maksimum 55 tahun (kecuali untuk pegawai Pemerintah / BUMN/ BUMD/ BHMN/ persyaratan usia ditentukan sesuai dengan ketentuan yang berlaku). 
- Penghasilan per bulan diatas Upah Minimum Regional (UMR) yang berlaku di daerah tersebut.

- Menyerahkan bukti diri berupa copy Kartu Tanda Penduduk (KTP) calon debitur dan suami/istri calon debitur, Kartu Keluarga (KK) serta Surat Nikah/Cerai (bagi yang sudah menikah/cerai).

- Jaminan yang digunakan khusus pegawai swasta cukup jamsostek ASLI, sedangkan untuk PNS jaminan yang digunakan adalah SK CPNS, PNS, TASPEN dan SK TERAKHIR

Fitur Kredit:

- Sifat kredit adalah aflopend plafond (angsuran tetap)

- Jangka waktu kredit maksimal 36 bulan untuk kredit usaha

- Jangka Waktu Kredit maksimal 60 bulan untuk pegawai tetap

- Jangka waktu sd 180 bulan atau 15 tahun untuk PNS

- Agunan adalah berupa objek yang dibiayai \& berupa fixed assets (untuk kredit Usaha)

Manfaat:

- Proses Cepat dan Mudah untuk kredit usaha maksimal 1 sd 2 minggu proses kredit dapat dicairkan

- Untuk proses kredit pegawai cukup waktu 2-3 hari kredit sudah dapat dicairkan langsung ke rekening debitur

- Persyaratan kredit yang ringan

\section{METODE PENELITIAN}

Analisa data dilakukan dengan mengunakan beberapa tehnik antara lain:

Uji Validitas dan Uji Realibilitas, Artinya pengukuran yang dapat diandalkan akan mengukur secara konsisten, tapi belum tentu mengukur apa yang seharusnya diukur. Dalam penelitian, reliabilitas adalah sejauh mana pengukuran dari suatu tes tetap konsisten setelah dilakukan berulang-ulang terhadap subjek dan dalam kondisi yang sama.

Dalam penelitian, data mempunyai kedudukan yang paling tinggi, karena data merupakan penggambaran variabel yang diteliti dan berfungsi sebagai alat pembuktian hipotesis. Benar tidaknya data, sangat menentukan bermutu tidaknya hasil penelitian. Sedang benar tidaknya data, tergantung dari baik tidaknya instrumen pengumpulan data. Pengujian instumen biasanya terdiri dari uji validitas dan reliabilitas.

Validitas adalah tingkat keandalah dan kesahihan alat ukur yang digunakan. Intrumen dikatakan valid berarti menunjukkan alat ukur yang dipergunakan untuk mendapatkan data itu valid atau dapat digunakan untuk mengukur apa yang seharusnya di ukur (Sugiyono, 2004:137). Dengan demikian, instrumen yang valid merupakan instrumen yang benar-benar tepat untuk mengukur apa yang hendak di ukur.

Penggaris dinyatakan valid jika digunakan untuk mengukur panjang, namun tidak valid jika digunakan untuk mengukur berat. 
Uji validitas dilakukan untuk mengukur apakah data yang telah didapat setela penelitian merupakan data yang valid dan alat ukur yang digunakan yaitu kuesioner (sugiyono,2007;121). Pengujian validitas dilakukan dengan menghitung korelasi antara masing-masing pernyataan dengan skor total. Adapun rumus dari pada korelasi pearson adalah sebagai berikut :

$$
r_{\mathrm{y}}=\frac{n \Sigma x y-\Sigma x y}{\sqrt{\left[n \Sigma x^{2}-(\Sigma x)^{2}\right]\left[\Sigma y^{2}-(\Sigma y)^{2}\right]}}
$$

Keterangan :

$\mathrm{r}=$ Koefisien Korelasi pearson

$\mathrm{X}=$ Skor Item Pertanyaan

$\mathrm{Y} \quad=$ Skor Total Pertanyaan

$\mathrm{N}=$ Jumlah Responden dalam pelaksanaan uji coba instrument

Nilai koefisien validitas paling kecil yang dianggap valid adalah $r>0,3$. Di mana disarankan bahwa koefisien korelasi antara 0,30 - 0,40 umumnya sudah tinggi (Kaplan - Saccuzzo 2009). Uji validitas Pengujian validitas merupakan pengujian yang dilakukan untuk mengukur apakah instrumen yang digunakan dalam penelitian benar-benar mampu mewakili semua aspek yang dianggap.

Setelah nilai koefisien realibilitas diperoleh, maka perlu ditetapkan suatu nilai koefisien reliabilitas paling yang paling kecil yang dianggap reliable.Nilai $\mathrm{r}>0,7$ dikatakan bahwa kuesioner reliable.

Uji Reliabilitas dilakukan untuk melihat apakah alat ukur yang digunakan (kuesioner) menunjukan konsistensi dalam mengukur gejala yang sama (sugiyono, 2007;124). Uji Reliabilitas digunakan untuk mengukur bahwa instrumen penelitian bebas dari kesalahan persepsi sehingga menghasilkan hasil yang konsisten dan dapat digunakan pada kondisi yang berbeda-beda. Untuk menguji reliabilitas akan digunakan Cronbach alpha dengan program SPSS. Instrumen dinyatakan reliabel apabila nilai alpha lebih besar dari 0,6 Rumus koefisien alpha

$$
R_{11}=\left(\frac{k}{k-1}\right)\left(\frac{\Sigma \sigma^{2} b}{\sigma t^{2}}\right)
$$

Keterangan :

dimana:

R11 = reliabilitas instrumen

$\mathrm{k}=$ banyaknya butir pertanyaan

$\sigma 2 b=$ jumlah varian butir

$\sigma \mathrm{t} 2=$ varian total

Setelah nilai koefisensi relaibilitas diperoleh, maka perlu ditetapkan suati nilai koefisiensi reliabilitas paling kecil yang dianggap realibel. Nilai $\mathrm{r}>0,7$ dikatakan bahwa kuesioner reliabel. Disarankan koefisensi reliabiltas antara 0,70 - 0,80 
cukup baik untuk tujuan penelitian dasar (kaplan Saccuzzo 2009 :264)

\section{HASIL DAN PEMBAHASAN}

Terdapat Pengaruh budaya organisasi terhadap kepuasan kerja di Divisi Mikro Bank Mandiri Area Cikini Jakarta Pusat di terima . Budaya organisasi adalah sebuah sistem makna bersama yang dianut oleh organisasi, yang membedakan antara satu organisasi dengan organisasi yang lain. Sebuah sistem makna bersama mengandung nilai-nilai, norma, adat, perilaku, sikap yang dipahami bersama dan menjadi komitmen bersama untuk bekerja dan berbuat dalam menghadapi tantangan organisasi baik itu secara internal ataupun eksternal. Dengan sistem makna bersama yang disepakati diharapkan organisasi dapat survive . Selain daripada sebagai sistem imun, sistem makna bersama itulah yang membedakan antara satu organisasi dengan organisasi yang lain.

Budaya organisasi menjadi perekat antar warga organisasi. Pada dasarnya manusia cenderung berkelompok dengan mereka yang memiliki kesamaan nilai, norma, adat, kepercayaan, dan asumsiasumsi yang lainnya. Kesamaan tersebut membawa individu-individu yang berbeda untuk menjalin kerjasama dalam mencapai tujuan organisasi. Jika hilang kebersamaan, dampaknya adalah terpecahnya atau bahkan musnahnya organisasi

1. Validitas dan Reliabilitas Variabel

\section{Kepuasan Kerja}

Validitas (Asep Hamdi dan E Bahrudin, 2014;65) adalah kesahihan berasal dari kata validity yang berarti sejauh mana ketepatan dan kecermatan suatu alat ukur dapat melakukan fungsi ukurnya. Validitas suatu instrumen atau tes mempermasalahkan apakah instrumen atau tes tersebut benarbenar mengukur apa yang hendak diukur, untuk melihat validitas instrument kepuasan kerja dapat dilihat pada tabel berikut :

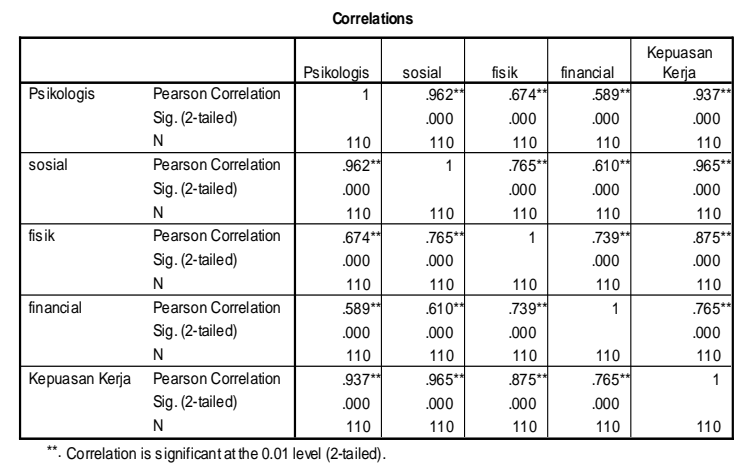

Berdasarkan tabel di atas dapat dilihat bahwa nilai korelasi dimensi Psikologis, social, fisik dan financial tingkat signifikasninya $0,000<0,05$ dapat disimpulkan valid. 
2. Faktor-faktor yang mempengaruhi Sumberdaya Manusia meliputi

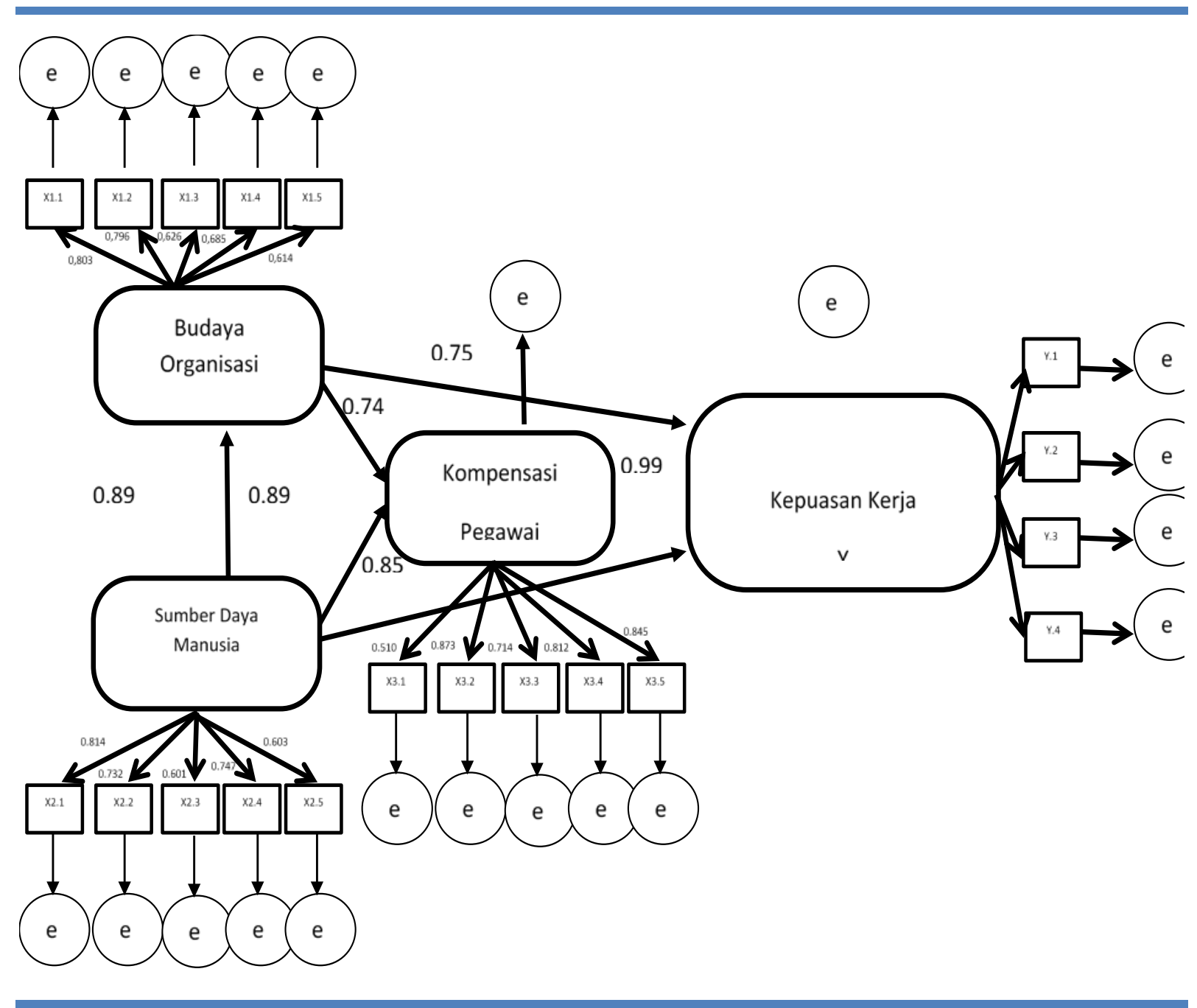

Berdasarkan gambar diatas dapat dijelaskan bahwa

1. Faktor-faktor yang mempengaruhi budaya organisasi meliputi Trust, Integriti, profesinalisme, focus dan excellent yang merupakan dimensi atau indicator yang dapat memepengaruhi budaya organisasi adapaun faktor yang paling dominan mempengaruhi budaya organisasi adalah faktor trust (Keprcayaan) sebesar 0,803.
Pendidikan, Lingkungan, Motivasi, Karakter dan Skill yang merupakan dimensi atau indicator yang dapat memepengaruhi sumber daya manusia adapaun faktor yang paling dominan mempengaruhi sumber daya manusia adalah faktor pendidikan sebesar 0,814 .

3. Faktor-faktor yang mempengaruhi kompensasi meliputi Gaji, Upah, Bonus, Tunjangan dan Pesangon 
yang merupakan dimensi atau indicator yang dapat memepengaruhi kompensasi adapaun faktor yang paling dominan mempengaruhi kompensasi adalah faktor Upah sebesar 0,845 .

4. Faktor-faktor yang mempengaruhi kepuasan kerja meliputi Psikologis, social, fisik dan financial yang merupakan dimensi atau indicator yang dapat memepengaruhi kepuasan kerja adapaun faktor yang paling dominan mempengaruhi kepuasan kerja adalah faktor Fisikologis sebesar 0,937.

\section{SIMPULAN}

Berdasarkan hasil penelitian dan analisis menggunakan SEM, maka dapat disimpulkan:

1. Terdapat pengaruh budaya kerja terhadap kepuasan kerja pegawai Mikro Bank Mandiri Area Jakarta Cikini

2. Terdapat pengaruh sumberdaya manusia secara signifikan terhadap kepuasan kerja pegawai Mikro Bank Mandiri Area Jakarta Cikini

3. Terdapat pengaruh Kompensasi terhadap kepuasan kerja pegawai Mikro Bank Mandiri Area Jakarta Cikini
4. Terdapat pengaruh budaya kerja, sumberdaya manusia dan kompensasi berpengaruh secara signifikan terhadap kepuasan kerja pegawai Mikro Bank Mandiri Area Jakarta Cikini

5. Terdapat pengaruh budaya kerja terhadap kepuasan kerja pegawai Mikro Bank Mandiri Area Jakarta Cikini

6. Terdapat pengaruh sumberdaya manusia secara signifikan terhadap kepuasan kerja pegawai Mikro Bank Mandiri Area Jakarta Cikini

7. Terdapat pengaruh Kompensasi terhadap kepuasan kerja pegawai Mikro Bank Mandiri Area Jakarta

Cikini

8. Terdapat pengaruh budaya kerja, sumberdaya manusia dan kompensasi berpengaruh secara signifikan terhadap kepuasan kerja pegawai Mikro Bank Mandiri Area Jakarta Cikini

\section{DAFTAR PUSTAKA}

Budisantoso, T dan Sigit. 2006. Bank dan Lembaga Keuangan Lain. Edisi 2. Jakarta Salemba Empat

F.X.Suwarto, D.Koeshartono, Budaya Organisasi .penerbit Universits Atma Jaya Yogyakarta

Hasibuan, Melayu SP. 2005. Dasar-dasar Perbankan.Jakarta: PT. Bumi Aksara. 
Kasmir. S.E., M.M. 2002. Dasar-Dasar Perbankan. Jakarta: PT. Raja Grafindo Persada

Kasmir. S.E., M.M. 2008. Bank dan Lembaga Keuangan Lainnya. Jakarta: PT. Raja Grafindo Persada

Henry Simamora , 2005) Manajemen Sumber Daya Manusia Edisi III Cetakan : Ke - 1. Penerbit STIE YKPN

Handoko, T. Hani, 2007. Manajemen Personalia dan Sumber Daya Manusia, Edisi kedua, BPFE, Yogyakarta

Hasibuan, Malayu S.P. 2012, Manajemen Sumber Daya Manusia. Jakarta: PT Bumi Aksara

Undang-Undang RI Nomor 10 Tahun 1998 (Acmadsobirin; 2007;) Edward B.Tylor Budaya Organisasi

Mangkunegara Anwar Prabu, 2011. Evaluasi Kinerja Karyawan SDM, Cetakan Kelima. Refika Aditama ; Jakarta

Mangkunegara Anwar Prabu, 2008. Manajemen Sumber Daya Manusia Perusahaan, Cetakan Keenam, PT. Remaja Rosdakarya, Bandung

Robbins dan Judge. 2008. Perilaku Organisasi, Edisi Duabelas, Penerbit Salemba Empat: Jakarta

Muhammad Arif, MA (www.doctorjambu. blogspot.com) 23 April 2018

G. Graham dalam Siswandi, 2010, Manajemen Perusahaan, edisi ke 3

Al-Quran Al Baqarah ayat 58

Al-Quran Yunus ayat 47- 49
Tika, Pabundu, 2006. Budaya Organisasi dan Peningkatan KinerjaPerusahaan. Bumi Aksara: Jakarta.

Brown, Dalam Masana, Kinerja Organisasi 2012, penerbit Fokusmedia 